\title{
Disturbance/Uncertainty Estimation and Attenuation Techniques in PMSM Drives-A Survey
}

\author{
Jun Yang, Member, IEEE, Wen-Hua Chen, Senior Member, IEEE, Shihua Li, Senior Member, IEEE, \\ Lei Guo and Yunda Yan, Student Member, IEEE
}

\begin{abstract}
This paper gives a comprehensive overview on disturbance/uncertainty estimation and attenuation (DUEA) techniques in permanent magnet synchronous motor (PMSM) drives. Various disturbances and uncertainties in PMSM and also other alternating current (AC) motor drives are first reviewed which shows they have different behaviors and appear in different control loops of the system. The existing DUEA and other relevant control methods in handling disturbances and uncertainties widely used in PMSM drives, and their latest developments are then discussed and summarized. It also provides in-depth analysis of the relationship between these advanced control methods in the context of PMSM systems. When dealing with uncertainties, it is shown that DUEA has a different but complementary mechanism to widely used robust control and adaptive control. The similarities and differences in disturbance attenuation of DUEA and other promising methods such as internal model control and output regulation theory have been analyzed in detail. The wide applications of these methods in different $\mathrm{AC}$ motor drives (in particular in PMSM drives) are categorized and summarized. Finally the paper ends with the discussion on future directions in this area.
\end{abstract}

Index Terms-Disturbances, uncertainties, PMSM drives, estimation, robustness, robust control, adaptive control.

\section{INTRODUCTION}

$\mathbf{W}$ ITH the increasing demands of higher precision machine drives, AC machine drives, which are widely considered as a substitute of direct current (DC) machine drives, are deemed as the most prevailing components of modern motion control systems due to many distinctive features they offer. Among various AC machine drives, PMSM has been receiving abundant attention because of its advantageous features including high efficiency, high power density, large torque-to-inertia ratio, low noise, and free maintenance [1][5]. As such, PMSM drives have been extensively applied to

Manuscript received October 9, 2015; revised January 11, 2016, February 21, 2016, April 11, 2016 and May 03, 2016; accepted May 17, 2016.

Copyright (c) 2015 IEEE. Personal use of this material is permitted. However, permission to use this material for any other purposes must be obtained from the IEEE by sending a request to pubs-permissions@ieee.org.

This work was supported in part by National Natural Science Foundation of China under Grants, 61203011, 61473080 and 61573099, PhD Program Foundation of Ministry of Education of China under Grant 20120092120031, Natural Science Foundation of Jiangsu Province under Grant BK2012327, China Postdoctoral Science Foundation under Grants 2013M540406 and 2014T70455, and a research grant from the Australian Research Council.

J. Yang, S. Li and Y. Yan are with School of Automation, Southeast University, Nanjing 210096, China (e-mails: j.yang84@seu.edu.cn, 1sh@seu.edu.cn and yyd@seu.edu.cn).

W.-H. Chen is with the Department of Aeronautical and Automotive Engineering, Loughborough University, Leicestershire, LE11 3TU, UK (email:w.chen@lboro.ac.uk).

L. Guo is with the School of Electrical Engineering and Automation, Beihang University, Beijing, China (e-mail: lguo@buaa.edu.cn). a variety of industrial sectors, such as robotics, machine tools, electrical vehicles, power generations and aerospace [4].

Despite many advantages described above, high precision control of PMSM drives is rather challenging because the motion dynamics of PMSM are complicated and intrinsically nonlinear, and, in addition, subject to various sources of disturbances and uncertainties [6]-[10]. Aiming to achieve desired servo control performance, apart from classical proportionalintegral-derivative (PID) controllers, plenty of advanced control algorithms have been put forward for AC machine drives, for example, model predictive control [5], [11], [12], robust and adaptive control [13]-[19], internal model control [20], output regulation [2], [21], disturbance observer-based control (DOBC) [4], [5], [22]-[32] and active disturbance rejection control (ADRC) [12], [33]-[36], to name but a few.

It has been widely recognized that a crucial task of controller design for PMSM systems is to reject various external disturbances and improve robustness in the presence of a wide range of uncertainties. The disturbances/uncertainties in AC machine drives, which usually exhibit different features, are generated from a wide range of sources including the changes of load, operational environments and the mechanical or electrical parts in the motor systems. In order to design a successful control algorithm and achieve desirable control performance, it is important to have a comprehensive understanding of the features of the disturbances/uncertainties in AC servo systems first. Consequently, the first focus of this paper is to provide a comprehensive overview of various kinds of disturbances/uncertainties in typical types of AC machine drives including PMSM, induction motor (IM) and brushless direct current motor (BLDCM). Among many advanced control strategies in dealing with disturbances and uncertainties, disturbance/uncertainty estimation and attenuation (DUEA) techniques have received considerable attention in AC machine drives during the past several decades. Here DUEA represents a category of algorithms/methods sharing a similar fundamental idea; that is, an observation mechanism is designed to estimate disturbances/uncertainties and corresponding compensation is then implemented by making use of the estimate [37]. Both DOBC and ADRC mentioned earlier belong to the category of DUEA. Since DUEA exhibits promising performance in handling disturbances and uncertainties [38], and it is not as well known as other methods for handling disturbances and uncertainties such as internal model control (IMC) and robust control, the second focus of this paper is to give a brief survey on the applications of DUEA and related techniques in PMSM drives. 
It is also noticed that understanding the relationships between different DUEA methods and other well established control methods in handling disturbances and uncertainties particularly in the context of motion control is of significant importance. It not only provides insight into the differences and similarities of those methods, but also, more importantly, guides researchers and engineers to identify and select most appropriate methods for applications in their hands. Accordingly, the next focus of this paper is to develop and present the relationships among these techniques. This part aims to not only give insight of the differences and similarities among different DUEA methods, but also discuss their links with many well known control methods. We will start with a general discussion on the basic features of DUEA in the comparison with robust control and adaptive control that are both proven to be effective in dealing with uncertainties, and then focus on two well established and closely related advanced control methods, namely internal model control (IMC) [39] and nonlinear output regulation (NOR) [40]. The last focus of the paper is on the application of the DUEA in several types of popular AC motor drives and a number of typical applications have been summarized.

The organization of the paper is as follows. In Section II, various disturbances and uncertainties existing in AC machine drives will be revisited. An overview of DUEA and related techniques for AC machine drives will be provided in Section III. Section IV focuses on exploring the relationships between DUEA methods and their relationships with other well known disturbance/uncertainty attenuation methods. In Section V, various applications of DUEA approaches in AC machine drives are presented, followed by concluding remarks and future directions in Section VI.

\section{Disturbances/Uncertainties in AC Machine DRIVES}

In most parts of the paper, we mainly focus on discussing PMSM system as a benchmark AC drive system. However, it is noticed that PMSM shares many similarities of the problem formulation, disturbance/uncertainty properties and control algorithms with a number of other advanced $\mathrm{AC}$ motor drives, such as IM, BLDCM, and switched reluctance motors [41]. For example, the differences and similarities among three most popular AC machine drives (PMSM, IM and BLDCM) are listed in Table I. In this section as well as several subsequent sections, attention to other $\mathrm{AC}$ motors will be paid for the interest of readers in related areas.

A generic $d-q$ dynamic model of PMSM drives is given with respect to its rotor reference frame as

$$
\begin{aligned}
\frac{d i_{d}}{d t} & =\frac{1}{L_{d}}\left(u_{d}-R_{s} i_{d}+n_{p} \omega L_{q} i_{q}\right), \\
\frac{d i_{q}}{d t} & =\frac{1}{L_{q}}\left(u_{q}-R_{s} i_{q}-n_{p} \omega L_{d} i_{d}-n_{p} \omega \psi_{f}\right), \\
\frac{d \omega}{d t} & =\frac{1}{J}\left(T_{e}-d_{T}^{\text {fric }}-d_{T}^{\text {load }}\right), \\
T_{e} & =\frac{3}{2} n_{p}\left[\psi_{f} i_{q}+\left(L_{d}-L_{q}\right) i_{d} i_{q}\right], d_{T}^{\text {fric }}=B_{v} \omega,
\end{aligned}
$$

TABLE II

DISTURBANCES AND UNCERTAINTIES IN PMSM

\begin{tabular}{lll}
\hline Symbol & Meaning & Unit \\
\hline$d_{T}^{\text {cog }}$ & Cogging Torque & $N \cdot m$ \\
$d_{\text {fux }}^{\text {fux }}$ & Flux Harmonic Torque & $N \cdot m$ \\
$d_{d V}^{\text {dead }}, d_{q V}^{\text {dead }}$ & Distortion Voltage & $V$ \\
$d_{d C}^{\text {offset }}, d_{q C}^{\text {offset }}$ & Current Offset Errors & $A$ \\
$d_{T}^{\text {fric }}$ & Friction Torque & $N \cdot m$ \\
$d_{T}^{\text {load }}$ & Load Torque & $N \cdot m$ \\
\hline
\end{tabular}

where $\omega$ is the rotor speed, $i_{d}$ and $i_{q}$ are stator currents in $d-q$ frame, $u_{d}$ and $u_{q}$ denote stator voltages in $d-q$ frame, $d_{T}^{\text {load }}$ represents the load torque disturbance, $d_{T}^{\text {fric }}$ is the friction torque disturbance, $T_{e}$ is the electromagnetic torque, $B_{v}$ is the frictional coefficient, $L_{d}$ and $L_{q}$ are stator inductances in $d-q$ frame, $R_{s}$ is the stator resistance, $\psi_{f}$ is the magnetic flux linkage, $J$ is the moment of the total inertial (rotor and load), and $n_{p}$ is the number of poles.

A basic field oriented control framework consisting of a speed loop and two current loops is shown in Fig. 1. The dynamics of PMSMs are essentially nonlinear subject to a wide range of disturbances/uncertainties in many high-performance applications. In this section, the disturbances/uncertainties in PMSM systems, which are classified as unmodelled dynamics, parametric uncertainties and external disturbances, are briefly reviewed first. The symbols, physical meanings and units of various disturbances/uncertainties are listed in Table II for the sake of clarity.

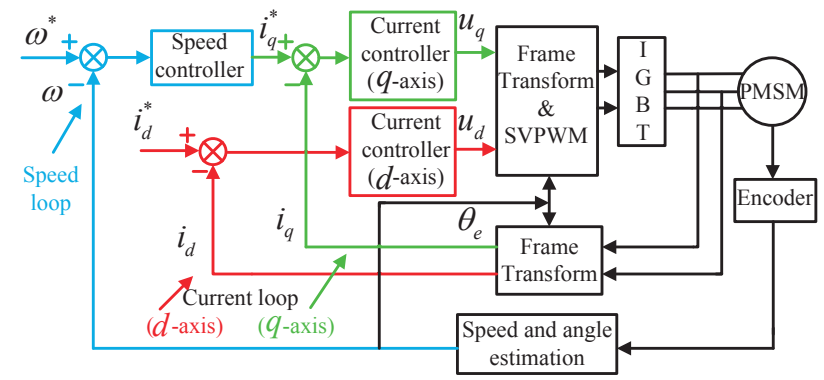

Fig. 1. Schematic diagram of PMSM based on vector control.

\section{A. Unmodeled Dynamics}

1) Motor Body Structure Induced Torque: Due to utilization of different rotor materials in AC motors, the body structure may induce various pulsating torques.

- Cogging Torque: As a kind of pulsating torque, cogging torque is basically generated by the interaction of the rotor magnetic flux and angular variations in the stator magnetic reluctance [42]. Note that cogging torque even exists when the system is disconnected from the power source. In general, this torque can be expressed as [6]

$$
d_{T}^{\mathrm{cog}}(N \cdot m)=\sum_{i=1}^{\infty} d_{T}^{\mathrm{cogi}} \sin \left(i N_{c} \theta_{e}\right)
$$

where $N_{c}$ is the least common multiple between the number of slots and pole pairs, $\theta_{e}$ is the electrical angle 
TABLE I

Differences and Similarities Between PMSM, IM ANd BLDCM Based on Field ORIENTEd Conrol

\begin{tabular}{|c|c|c|c|c|c|c|}
\hline \multirow{2}{*}{$\begin{array}{l}\text { Motor } \\
\text { Type }\end{array}$} & \multicolumn{2}{|l|}{ Motor Body } & \multicolumn{2}{|l|}{ Disturbances/Uncertainties } & \multicolumn{2}{|c|}{ Control } \\
\hline & Rotor Type & $\begin{array}{c}\text { Dynamic } \\
\text { Models } \\
\end{array}$ & Caused by Motor Body Structure & Others & $\begin{array}{c}\text { Rotor Flux Position } \\
\text { Measurement }\end{array}$ & $\begin{array}{c}\text { Control } \\
\text { Algorithms }\end{array}$ \\
\hline IM & $\begin{array}{l}\text { Aluminum/ cuprum windings } \\
\text { (' }{ }^{1} \text { wound-rotor }{ }^{2} \text { squirrel cage) }\end{array}$ & $\begin{array}{c}4 \text { th } \\
\text { order }\end{array}$ & Skewed Slot Torque & \multirow{3}{*}{ Similar } & Direct/Indirect & \multirow{3}{*}{ Similar } \\
\hline PMSM & \multirow[b]{2}{*}{ PM material } & \multirow[b]{2}{*}{$\begin{array}{l}3 \text { rd } \\
\text { order }\end{array}$} & ${ }^{1}$ Cogging Torque $/{ }^{2}$ Flux Harmonics & & \multirow[b]{2}{*}{ Direct } & \\
\hline BLDCM & & & $\begin{array}{c}{ }^{1} \text { Cog ging Torque } /{ }^{2} \text { Commutation } \\
\text { Torque }{ }^{\beta} \text { Nonideal Trapezoidal Back } \\
\text { Electromotive Force }\end{array}$ & & & \\
\hline
\end{tabular}

denoted by $\theta_{e}(t)=\theta_{e}\left(t_{0}\right)+\int_{t_{0}}^{t} n_{p} \omega(\tau) d \tau$ and $d_{T}^{\text {cogi }}$ is the amplitude of the $i$ th-order harmonic cogging torque. There is no cogging torque in induction motors. However, the skewed slot torque in IM has a similar structure and property as the cogging effects in PMSM [43].

- Flux Harmonics: The most widely used material in the magnet of PMSM is Neodymium Iron Boron and its flux density is easily affected by the temperature variation. The resultant demagnetization phenomenon of permanent magnets due to temperature rise has a significant impact on the maximum torque capability and the efficiency of PMSM [44]. The flux linkage between the rotor and stator magnets can be expressed as [7], [45]

$$
\psi_{f}=\sum_{i=0}^{\infty} \psi_{f i} \cos \left(6 i \theta_{e}\right)
$$

where $\psi_{f i}$ is the amplitude of the $6 i$ th-order harmonic flux. According to the definition of electromagnetic torque $T_{e}$, it is indicated by (1) that the effect of flux harmonics can be represented as follows

$$
d_{T}^{\text {flux }}(N \cdot m)=\frac{3}{2} n_{p} i_{q} \sum_{i=1}^{\infty} \psi_{f i} \cos \left(6 i \theta_{e}\right) .
$$

- Others: For BLDCM systems, in addition to cogging torque, there are mainly two other causes of pulsating torque. One is commutation torque which is caused by the different current slew rates between switching-in phase and switching-out phase [46]-[48]. Another is nonideal trapezoidal back electromotive force due to stator winding action, the magnetization direction of rotor permanent magnets, and imperfections in machine manufacturing [49], [50].

2) Dead-Time Effects: The dead-time causes a loss of a portion of the duty cycle and distortion of the voltage applied to the drives [8], [51]-[53]. Note that such effects become extreme severe near the zero crossing of the current. The resultant current deterioration finally leads to the ripples in the electromagnetic torque. The dead-time effect can be represented on stator voltage channels in the $d-q$ frame as follows [8], [53]

$$
\begin{aligned}
& d_{d V}^{\text {dead }}(V)=\sum_{i=0}^{\infty} d_{d i} \sin \left(6 i \theta_{e}\right), \\
& d_{q V}^{\text {dead }}(V)=\sum_{i=0}^{\infty} d_{q i} \cos \left(6 i \theta_{e}\right),
\end{aligned}
$$

where $d_{d i}$ and $d_{q i}$ are the amplitudes of 6ith-order harmonic signals of $d_{d V}^{\text {dead }}$ and $d_{q V}^{\text {dead }}$, respectively.

3) Measurement Error Effects: In AC servomotors, the errors in measurements of either position or current inevitably cause torque ripples. As an example, the offset error in current measurements is taken to illustrate the adverse effects of measurement errors. The offset errors superimposing directly on the phase currents via the transform of Clarke and Park, cause ripples on stator currents in $d-q$ frames [7], [9], [42], which can be modeled as [7]

$$
\begin{aligned}
& d_{d C}^{\text {offset }}(A)=d^{\text {offset }} \sin \left(\theta_{e}+\alpha\right), \\
& d_{q C}^{\text {offset }}(A)=d^{\text {offset }} \cos \left(\theta_{e}+\alpha\right),
\end{aligned}
$$

where $\alpha$ is a constant angular displacement and $d^{\text {offset }}$ is the amplitude of ripple.

\section{B. Parametric Uncertainties}

1) Mechanical Parameters: The inertia $J$ of a PMSM system, including both rotor and load, is usually a constant during a short-term operation process. However, in some special applications, e.g., electric winding machine, the inertia of the whole system is time-varying, for example, increase as time goes by in [1], [20]. If the inertia of the system increases to several times of the original inertia, the speed response will have a bigger overshoot and a longer settling time [1], [20].

2) Electrical Parameters: The thermal model of AC machines has a significant impact on the motor controller design [54], [55]. The thermal model of AC machines is incorporated in the nominal models used for control design, and improves the performance of disturbance/uncertainty estimation. For example, the stator resistance $R_{s}$ varies primarily with winding temperature while a small amount of skin and stray loss effects are neglected [2]. The resistance $R_{s}$ at temperature $T$ can be written as [44]

$$
R_{s}=R_{0}(235+T) /\left(235+T_{0}\right),
$$


where $R_{0}$ is the resistance at temperature $T_{0}$. It can be observed from the PMSM model (1) that the stator resistance affects the plant bandwidth of the current loop directly. As such, the variation of stator resistance has a great impact on the current-loop regulation performance. Moreover, the resistance effect becomes much severe at low speeds or in high load torque conditions [2], [3], [56].

In addition, the stator inductances $L_{d}$ and $L_{q}$ are hard to precisely obtain [57], and they are usually functions of current magnitude and current phase angle of the motor [2], [4]. For instance, the effects of cross saturation [58] generally result in variations of stator inductances which affects both the plant gain and the open-loop electrical time constant of the motor, and hence, the performance of the drives at different operating conditions.

\section{External Disturbances}

1) Friction Torque: Friction is the tangential reaction force between two surfaces in contact [59]. It can be represented by static models (the Coulomb model, the Stribeck model, the Karnppp model, etc.) and dynamic models (the Dahl model, the Bristle model, the reset integrator model, and the LuGre model, etc.) [59]. The nonlinear effects of friction are unavoidable and widely exist in servo systems, which may cause steady-state errors, tracking lags and limit cycles in position regulation [59], [60]. Taking the Stribeck model as an example, the friction torque $d_{T}^{\text {fric }}$ is expressed as [59]

$$
d_{T}^{\mathrm{fric}}(N \cdot m)=\left(T_{c}+\left(T_{s}-T_{c}\right) e^{-\left(\frac{\omega}{\omega_{s}}\right)^{2}}\right) \operatorname{sign}(\omega)+B_{v} \omega,
$$

where $T_{s}$ is the static friction torque, $T_{c}$ is the Coulomb friction torque, $\omega_{s}$ is the Stribeck velocity, and $\operatorname{sign}(\bullet)$ is the standard signum function.

2) Load Torque: Torque on the load side is generally deemed as one of the most severe disturbances affecting the dynamic performance. For example, since the transmission mechanism is not an ideal rigid body, mechanical resonance can be easily excited due to the load torque [10]. Speed is inevitably changed when load torque is imposed on the motor.

3) Mechanical Factors: The effects raised by mechanical characteristics such as torsional vibrations, backlash, and uncertainties generated by misalignment of shaft, broken shaft and twisted shaft are another branch of causes restricting servo performance improvement of motor drives [61]. It is estimated that the misalignment of shaft causes over $70 \%$ of rotating machinery's vibration problems in industrial motor drives [62].

Distribution of Disturbance/Uncertainty in PMSM: The disturbance/uncertainty discussed above affect the PMSM system via different control loops. Malposed compensation of the disturbance/uncertainty definitely results in performance degradation of the servo system. As such, it is of great importance to know the distribution of disturbance/uncertainty in PMSMs. A diagram of the distribution of unmodeled dynamics and external disturbances in PMSM systems is shown in Fig. 2 (the scenario of $d$ frame current loop is ignored for simplicity). Clearly, the cogging torque, flux harmonics, friction torque, and load torque affect the PMSM system in the speed loop. The dead-time effect and offset error of Hall current sensors affect the PMSM system in the current loops. As mentioned above, disturbances/uncertainties are distributed in different control loops (speed and current loops) and appears in different forms (e.g., slowly-varying and periodic), which imposes challenges in disturbances/uncertainties attenuation for PMSM.

Generally speaking, disturbances/uncertainties attenuation for PMSMs can be divided into two groups [7], [42]: improving motor design and using advanced control strategies. This paper focuses on the later one.

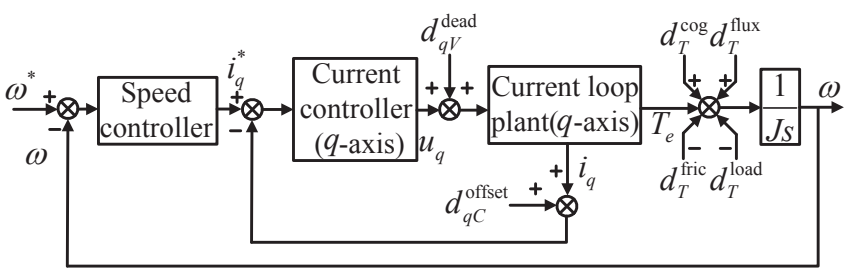

Fig. 2. The distribution of disturbance/uncertainty in PMSM systems.

\section{AN OVERVIEW ON DUEA AND RELATED TECHNIQUES IN PMSM DRIVES}

This part will give a brief overview on DUEA and related techniques in PMSM drives. Section III-A is devoted to DUEA while other widely used control methods for handling disturbances and uncertainties in PMSM drives are covered in Section III-B.

\section{A. DUEA Methods in PMSM Drives}

A number of DUEA techniques have been proposed since 1960s based on different disturbance/uncertainty estimators, including

- DOBC [63];

- extended state observer-based control (ESOBC, also called ADRC) [64];

- unknown input observer-based control (UIOBC) [65];

- generalized proportional integral observer-based control (GPIOBC) [66];

- equivalent input disturbance-based control (EIDBC) [67];

- uncertainty and disturbance estimator-based control (UDEBC) [68];

- sliding mode disturbance observer-based control (SMDOBC) [69];

- intelligent disturbance observer-based control (IDOBC) [70];

and so on. Different from other control methods in handling disturbances and uncertainties, some of which are going to be discussed in the next section, this group of algorithms is featured with a built-in estimation mechanism for the lumped disturbance and the influence of uncertainties [37]. In this survey paper, we aim to elaborate the similarities/differences among different DUEA and related methods rather than their detailed algorithms. The readers are referred to see the survey paper [37] for a comprehensive overview on these DUEA techniques. Among those DUEA techniques, DOBC and ADRC have received most extensive investigations and applications in $\mathrm{AC}$ machine drives. 
1) $D O B C$ : As a key component of DOBC, DOB was initiatively put forward by $\mathrm{K}$. Ohnishi and his colleagues in 1980s to improve disturbance rejection and robustness in DC motors [63]. The early DOBC was designed on the basis of frequency-domain control theory. With the prevalence of state space design approaches for DOBC, nonlinear DOBC has attracted a great deal of attentions so as to further enhance the control performances of essential nonlinear dynamic systems. In what follows, we will try to illustrate the basic principles of typical frequency-domain DOBC and nonlinear DOBC via two benchmark design examples of the speed regulation of the PMSM system.

Frequency-Domain DOBC (FDDOBC): The nominal model utilized for FDDOBC design is generally linear one, while the nonlinearities of the motor plant are usually treated as a part of the lumped disturbances, which are estimated and attenuated in the same manner as external disturbances. A design example of FDDOBC for PMSM speed regulation is presented as follows.

Example 1 (FDDOBC): Taking the speed regulation problem of the PMSM system (1) as a benchmark example, the dynamic model of the speed loop is given by

$$
J \dot{\omega}=K_{t} i_{q}-B_{v} \omega+\frac{3}{2} n_{p}\left(L_{d}-L_{q}\right) i_{d} i_{q}-T_{L}+\varepsilon_{\omega},
$$

where $K_{t}=3 n_{p} \psi_{f} / 2$, and $\varepsilon_{\omega}$ denotes the unmodeled dynamics in speed channel. Denoting the current control signal in $q$ frame as $i_{q}^{*}$, we have

$$
J \dot{\omega}=K_{t}\left(i_{q}^{*}+d\right)-B_{v} \omega,
$$

with the disturbance term

$$
d(t)=\frac{1}{K_{t}}\left[K_{t}\left(i_{q}-i_{q}^{*}\right)+\frac{3}{2} n_{p}\left(L_{d}-L_{q}\right) i_{d} i_{q}-T_{L}+\varepsilon_{\omega}\right],
$$

where $\varepsilon_{\omega}$ denotes the unmodeled dynamics in the speed loop. Let $y=\omega$ and $u=i_{q}^{*}$. The transfer function model of (3) is written as

$$
y(s)=G(s)[u(s)+d(s)], G(s)=K_{t} /\left(J s+B_{v}\right) .
$$

The frequency-domain DOBC for the above speed regulation system is designed and shown in Fig. 3.

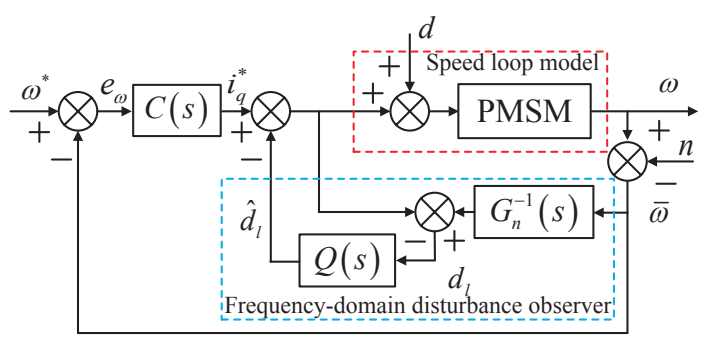

Fig. 3. Structure diagram of FDDOBC for a PMSM.

Besides the disturbance term $d(t)$, the parameters $J, B_{v}$ and $K_{t}$ also have uncertainties in practice. Consequently, as shown in Fig. 3 the nominal model

$$
G_{n}(s)=K_{t o} /\left(J_{o} s+B_{v o}\right),
$$

with the nominal values of $J_{o}, B_{v o}$ and $K_{t o}$ is usually employed in DOB design.
As shown by Fig. 3, the frequency-domain DOB is employed to estimate the total disturbances/uncertainties including load toque disturbance, additional nonlinear dynamics, parametric uncertainties, and even couplings from the current loop of PMSM in the above example. It follows from Fig. 3 that

$$
d_{l}(s)=\left[G_{n}^{-1}(s)-G^{-1}(s)\right] y(s)+d(s)-G_{n}^{-1}(s) n(s) .
$$

The first item relates to the mismatching between the physical system $G(s)$ and the nominal model $G_{n}(s)$, the second the external disturbance $d(s)$, and the last the measurement noise $n(s)$. Therefore, $d_{l}$ captures all the disturbance and uncertainty influence. After letting it pass a filter $Q(s)$, the estimate of the lumped disturbance in DOB is given by

$$
\hat{d}_{l}(s)=G_{u \hat{d}}(s) u(s)+G_{y \hat{d}}(s) \bar{y}(s),
$$

where

$$
G_{u \hat{d}}(s)=-Q(s), G_{y \hat{d}}(s)=G_{n}^{-1}(s) Q(s) .
$$

The design of the filter $Q(s)$ plays a central role in DOB. In general, the design criterion of filter $Q(s)$ can be summarized as follows:

- the filter $Q(s)$ shall be designed as a low-pass filter with its relative degree (i.e. the order difference between the denominator and the numerator of its transfer function) higher than that of the nominal motor plant $G_{n}(s)$;

- the cut-off frequency of the low pass filter $Q(s)$ is crucial in trading off between different factors (e.g. stability and performance requirements, frequency characteristic of the load toque disturbance and measurement noise, the size and characteristic of nonlinearities and uncertainties). In general, high cut-off frequency increases the disturbance attenuation and robustness, but demands large control action and increases sensitivity to the sensor noise.

Various guidelines and methods for designing the filter $Q(s)$ can be found in [63], [71], [72] to name but only a few. The utilization of frequency-domain DOBC to improve robustness and disturbance rejection performance of AC servo systems has been extensively investigated in literatures (see [22]-[26] for recent advances).

Nonlinear $D O B C$ (NDOBC): The nonlinear part of a $\mathrm{AC}$ motor drive system can be deliberately ignored and deemed as a part of "lumped" disturbances, and then the above FDDOBC techniques can be applied to estimate the influence of the ignored nonlinearities so an appropriate action can be generated to compensate for that. However, for most of $\mathrm{AC}$ motor drive systems, the nonlinear dynamics may be known or at least partially known. The estimation and attenuation of real external unknown disturbance and uncertainty (or unmodeled dynamics) can be significantly improved if the (known) nonlinear dynamics could be exploited in design. This motivates the development of state-space DOBC, in particular NDOBC techniques for $\mathrm{AC}$ motor drives with nonlinear dynamics.

Example 2 (NDOBC): Here again, we consider the speed regulation problem of the PMSM system (1) as a benchmark example to illustrate the basic idea of NDOBC. The dynamic 
model of the motor drive (1) is rewritten as

$$
\begin{aligned}
\frac{d i_{d}}{d t} & =\frac{1}{L_{d o}}\left(u_{d}-R_{s o} i_{d}+n_{p} \omega L_{q o} i_{q}+f_{d}\right), \\
\frac{d i_{q}}{d t} & =\frac{1}{L_{q o}}\left(u_{q}-R_{s o} i_{q}-n_{p} \omega L_{d o} i_{d}-n_{p} \omega \psi_{f o}+f_{q}\right), \\
\frac{d \omega}{d t} & =\frac{1}{J_{o}}\left[K_{t o} i_{q}-B_{v o} \omega+\frac{3}{2} n_{p}\left(L_{d o}-L_{q o}\right) i_{d} i_{q}+f_{\omega}\right],
\end{aligned}
$$

where $R_{s}=R_{s o}+\Delta R ; L_{d}=L_{d o}+\Delta L_{d} ; L_{q}=L_{q o}+\Delta L_{q}$; $\psi_{f}=\psi_{f_{o}}+\Delta \psi ; K_{t}=K_{t o}+\Delta K ; K_{t o}=3 n_{p} \psi_{f_{o}} / 2$; and $f_{d}, f_{q}$ and $f_{\omega}$ denote lumped disturbances

$$
\begin{aligned}
f_{d}= & \Delta L_{q o} n_{p} \omega i_{q}-\Delta R i_{d}-\Delta L_{d} \frac{d i_{d}}{d t}+\varepsilon_{d}, \\
f_{q}= & -\Delta L_{d o} n_{p} \omega i_{d}-\Delta R i_{q}-\Delta L_{q} \frac{d i_{q}}{d t}-\Delta \psi n_{p} \omega+\varepsilon_{q}, \\
f_{\omega}= & \Delta K i_{q}+\frac{3}{2} n_{p}\left(\Delta L_{d}-\Delta L_{q}\right) i_{d} i_{q}-\Delta B_{v} \omega \\
& -T_{L}-\Delta J \frac{d \omega}{d t}+\varepsilon_{\omega} .
\end{aligned}
$$

where $\varepsilon_{d}$ and $\varepsilon_{q}$ denote the unmodeled dynamics in $d$ and $q$ current channels, respectively. Let $x=\left[i_{d}, i_{q}, \omega\right]^{\top}, u=$ $\left[u_{d}, u_{q}\right]^{\top}$ and $d=\left[f_{d}, f_{q}, f_{\omega}\right]^{\top}$. The dynamic models (7) can be represented in the following compact form

$$
\dot{x}=f(x)+g_{1}(x) u+g_{2}(x) d .
$$

The nonlinear disturbance observer (NDOB) is designed as [73]

$$
\begin{aligned}
& \dot{z}=-l(x)\left[g_{2}(x)(p(x)+z)+f(x)+g_{1}(x) u\right], \\
& \hat{d}=z+p(x),
\end{aligned}
$$

where $p(x)$ is a nonlinear function to be designed. The observer gain $l(x)$ is determined by $l(x)=\partial p(x) / \partial x$. It has been shown in [74] that the NDOB asymptotically estimates the disturbance if the disturbance is constant and the observer gain $l(x)$ is chosen such that

$$
\dot{e}_{d}=-l(x) g_{2}(x) e_{d}
$$

is asymptotically stable regardless of $x$ where $e_{d}=d-\hat{d}$ is the disturbance estimation error.

There are many ways to choose the nonlinear gain $l(x)$ such that Eq. (10) is asymptotically stable. Since $g_{2}(x)$ is a constant matrix here, we can design a very simple linear gain $l$ such that the matrix $l g_{2}$ is Hurwitz stable. The block diagram of NDOBC for the PMSM system is shown by Fig. 4. The utilization of NDOBC-like approaches to AC motor drives can be seen from [4], [5], [27]-[32].

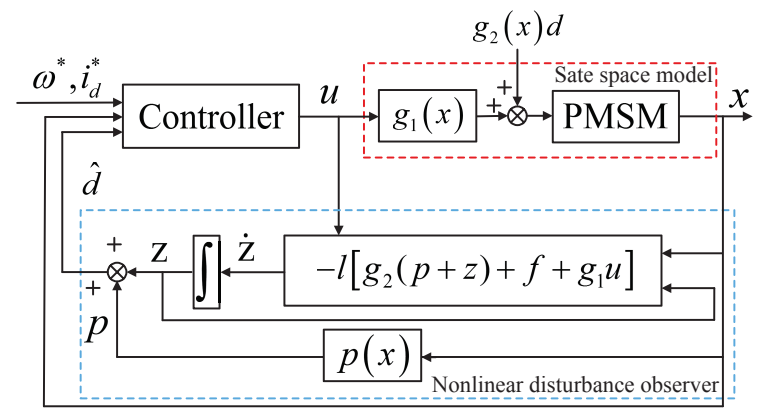

Fig. 4. Structure diagram of NDOBC for a PMSM.
2) ADRC: The concept of ADRC [64], [75] was firstly proposed by J. Han in the 1990s, aiming to develop an alternative practical control method to classic PID. In the framework of ADRC, extended state observer (ESO) is generally regarded as a fundamental part, which was developed to estimate the lumped disturbances consisting of both nonlinearities and external disturbances. The basic design principle of ESO for motor drives can be seen from the following example.

Example $3(A D R C)$ : We consider a direct drive of PMSM system (1), that is, the voltage signal $u_{q}$ is employed to regulate the rotor speed $\omega$ directly. The dynamic model is rearranged and given by

$$
\ddot{y}(t)=f(y(t), \dot{y}(t), t)+b u(t),
$$

where $y(t)=\omega(t), u(t)=u_{q}(t), b=K_{t o} /\left(J_{o} L_{q o}\right)$ and

$$
\begin{aligned}
f= & \left(\frac{K_{t}}{J L_{q}}-\frac{K_{t o}}{J_{o} L_{q o}}\right) u_{q}+\frac{1}{J}\left[-B_{v} \frac{d \omega}{d t}-\frac{d T_{L}}{d t}\right. \\
& +\frac{K_{t}}{L_{q}}\left(-R_{s} i_{q}-n_{p} \omega L_{d} i_{d}-n_{p} \omega \psi_{f}\right) \\
& \left.+\frac{3}{2} n_{p}\left(L_{d}-L_{q}\right)\left(i_{d} \frac{d i_{q}}{d t}+i_{q} \frac{d i_{d}}{d t}\right)\right]+\varepsilon_{f},
\end{aligned}
$$

where $\varepsilon_{f}$ denotes the lumped unmodeled dynamics. Note that besides the disturbances/uncertainties described in Section II, the nonlinear coupling dynamics from $d$-frame are also considered as a part of the lumped disturbance here. Letting $x=[y, \dot{y}]^{\top}$ and $d=f$, the dynamic model is rewritten as

$$
\dot{x}=A x+B_{u} u+B_{d} d, y=C x,
$$

where

$$
A=\left[\begin{array}{ll}
0 & 1 \\
0 & 0
\end{array}\right], B_{u}=\left[\begin{array}{l}
0 \\
b
\end{array}\right], B_{d}=\left[\begin{array}{l}
0 \\
1
\end{array}\right], C=\left[\begin{array}{l}
1 \\
0
\end{array}\right]^{\top}
$$

Choose the disturbance $d$ as a new state and define $\bar{x}=$ $\left[x^{\top}, d\right]^{\top}$. The augmented system is expressed as

$$
\dot{\bar{x}}=\bar{A} \bar{x}+\bar{B} u, y=\bar{C} \bar{x},
$$

where

$$
\bar{A}=\left[\begin{array}{cc}
A & B_{d} \\
0 & 0
\end{array}\right], \bar{B}=\left[\begin{array}{c}
B_{u} \\
0
\end{array}\right], \bar{C}=[C, 0] .
$$

ESO is designed to estimate all the states and lumped disturbance term $f$, given by [64], [75]

$$
\dot{\overline{\bar{x}}}=\bar{A} \hat{\bar{x}}+\bar{B} u+L(y-\hat{y}), \hat{y}=\bar{C} \hat{\bar{x}},
$$

where $\hat{\bar{x}}$ is the estimate of both the states and lumped disturbances, and $L$ is the observer gain to be designed. It is easy to see the estimate of lumped disturbances is

$$
\hat{d}=E_{3} \hat{\bar{x}},
$$

where $E_{3}=[0,0,1]$. The block diagram of ADRC for the PMSM system is shown by Fig. 5 .

It is obvious that both the influences of model dynamics (including unmodelled dynamics and uncertainty) and external disturbances are estimated by the ESO. Only the relative degree of the system under consideration is required in the ESO design. So the significant feature of ESO is that it requires a minimum information about a dynamic system. Various extensions have been made to extend the basic ESO design to a wider range of dynamic systems. For more information 
about ESO and related ADRC, please refer to the recent survey paper [76]. Application of ADRC to AC motor drive systems can be referred to [12], [33]-[36].

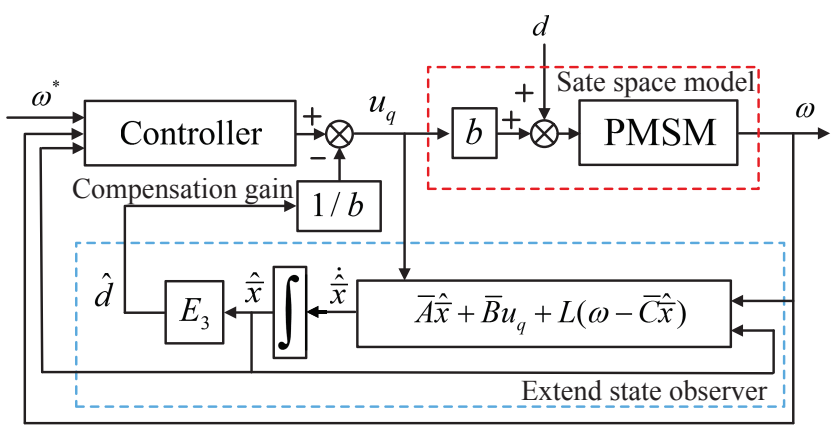

Fig. 5. Structure diagram of ADRC for a PMSM.

\section{B. Other Related Methods in AC Machine Drives}

In addition to DUEA approaches, many other related methods, most notably robust and adaptive control, internal model control, and output regulation, are extensively utilized to handle various disturbances/uncertainties in AC servo systems. Since those advanced control approaches for handling disturbances/uncertainties have been extensively discussed in various papers and books [41], [77], instead of paying too much attention on the details of each algorithms and their applications, this paper mainly focus on discussing the similarities/differences among them and DUEAs.

1) Robust Control and Adaptive Control: As both robust control and adaptive control have reached a relatively mature level, it is not surprising that both robust control and adaptive control approaches have been massively investigated in AC machine drives, for examples, see [11], [13]-[19], [78]. The basic idea of robust and adaptive control is quite intuitive; that is, robust control is employed to suppress disturbances and uncertainties, while adaptive control is applied for further improvement of precision by on-line identifying some key parameters such as inertial moment [79]. General discussions on relevances between DUEA and robust and adaptive control are presented in Section IV-A.

2) Internal Model Control (IMC): IMC is a quite popular and widely used method due to its simple concept and intuitive design philosophy. In the early 1980s, the idea of IMC was proposed by Garcia and Morari to attenuate the effects of external disturbances in control systems [39]. The block diagram of an IMC approach applied to PMSM is shown by Fig. 6.

By properly designing the filter $F(s)$ and controller $C(s)$, the IMC approach could achieve desired disturbance rejection and reference tracking performances. The application of IMC to AC servo systems can be found from [20] for an instance. The relationship between IMC and DOBC will be further discussed in Section IV-B.

3) Output Regulation and Internal Model Principle: The output regulation problem is also called the servomechanism problem, which aims to design a feedback controller to achieve

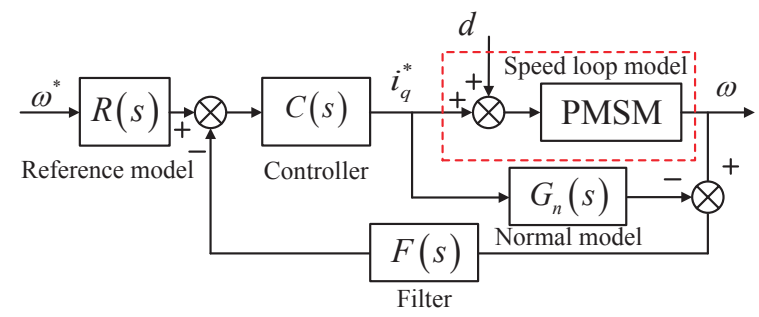

Fig. 6. Block Diagram of IMC for a PMSM.

asymptotic tracking and disturbance rejection for uncertain systems [80]. The internal models of references and external disturbances are usually incorporated into the controller design of output regulation approaches so as to achieve asymptotic tracking and disturbance compensation. The design philosophy of robust control is usually applied for output regulation to achieve robustness against various model uncertainties. The applications of output regulation and internal model principle to AC servo systems can be seen from [2], [21] for examples. A comparison study between nonlinear output regulation and nonlinear DOBC will be elaborated in Section IV-C.

\section{DUEA And Related Methods-Relevances And DISCUSSIONS}

\section{A. DUEA Versus Robust and Adaptive Control}

1) Backgrounds: An attractive feature of DUEA methods is that the influence of uncertainty is considered to be a part of lumped disturbances so it is able to estimate the influence of uncertainty and improve robustness for uncertain systems including parameter uncertainties, unmodelled dynamics and other variations. This section focuses on the robustness of DUEA in the presence of only uncertainty. Dealing with uncertainty has been a center of control engineering, and numerous methods/algorithms have been proposed. In a quite broad sense, these methods fall into two categories: robust control and adaptive control.

Robust control aims at designing a (fixed) controller that is not sensitive to uncertainty so stability and satisfactory performance is maintained under the uncertainty. In general, robust control is the worst case design; that is, the controller is designed to achieve best robust performance under all the possible variations (i.e. concerning the worst performance under all the described uncertainty). Although this design philosophy gives the best possible robustness performance, it may be overly conservative. The nominal performance may have to be sacrificed in order to achieve the best possible robustness (due to the design conflictions as discussed in [81]). Industrial systems may operate close to the nominal working conditions in most of their operation and only operate in the extreme conditions occasionally. Over concentrating on the worst case implies that the control systems may achieve degraded performance in most of the operational time.

In contrast, adaptive control aims to online adjust a control mechanism (e.g. tuning controller parameters) based on realtime input and output data of an uncertain system. Ideally, the control law can follow the changes of the controlled plant 
so a good performance (or even the optimal performance in some sense) can be achieved under all the possible variations. However, most of the existing adaptive control techniques focus on linear or nonlinear systems with linear unknown parameters (i.e. the uncertainty enters the system not only with a known structure but also being expressed as linear functions of uncertain parameters). Unfortunately, the uncertainty in real AC motor applications could be quite complicated and does not necessarily satisfy these conditions; for example, the dynamic system may have unmodelled dynamics (or high order dynamics are ignored for the ease of control strategy development). An adaptive control system may become unstable in applications in the presence of unstructured uncertainty or disturbances.

2) Relevances and Discussions: DUEA is a methodology between robust control and adaptive control. This explains the fact that although, in most cases, it is regarded as a robust control method due to its promising robustness, it is also regarded as an adaptive control method by some researchers (for example, [82]). As an alternative methodology to robust control and adaptive control, DUEA can alleviate some shortcomings in robust control and adaptive control described above. This can be explained by using the basic diagram of DOBC as in Fig. 3 by ignoring both sensor noise and external disturbance. The inner disturbance observer loop acts as an adaption mechanism in the presence of uncertainty. Rather than directly estimating the uncertain parameters as in many adaptive control algorithms, as shown in Eq. (4), it estimates the total difference between the nominal model $G_{n}(s)$ and the physical system $G(s)$, which may include both structured or unstructured uncertainty. So it is a "crude" adaptive control mechanism. Although it might not achieve the same control performance as other adaptive control algorithms when the uncertainty is structured (e.g. represented by linear functions of unknown parameters), it is more robust than most of adaptive control algorithms. On the other side, as the inner loop is not activated when there is no difference between the nominal model and the physical system, the nominal tracking and regulation performance is maintained. In the presence of uncertainties, the inner disturbance observer loop is activated to estimate and attenuate the influence of the uncertainty. Therefore, compared with robust control methods that are based on the worst case design, the robustness of DUEA may be not as good as these methods since they are designed to achieve best possible robust performance in the presence of the worst uncertainty. So in the sense, DUEA can be regarded as a "refined" robust control method. However, it provides a promising approach for trading off between the nominal performance and robustness. In a summary, DUEA provides an alternative approach to widely used robust control and adaptive control methods for dealing with uncertain (linear or nonlinear) systems.

The differences in design philosophies/control performances between DUEA and robust and adaptive control approaches are elaborated in more details using speed regulation of PMSM system as an example.

- Robust Control: The disturbances (e.g. load torque) and uncertainties (unmodeled dynamics, e.g. pulsating torques; and parameter perturbations, e.g. inertia variations) in PMSM are supposed to be bounded or bounded by a function. A performance index aiming to minimize the undesirable influence on motor speed in the presence of worst-case disturbances/uncertainties is developed for robust controller design, e.g. [13]. The robust controller achieves prominent speed regulation performance in the presence of large disturbances/uncertainties, but relatively poor nominal regulation performance since the nominal case is not explicitly considered in the performance index. In addition, such a controller generally produces a relatively higher control energy due to the conservative design.

- Adaptive Control: Adaptive control mainly focuses on handling the undesirable performance caused by parameter changes in motor drives. For example, the inertia moment would change up to several times of its nominal value. An adaptive update law is developed to estimate the unknown parameters, and the estimate of which is then utilized to construct the adaptive servo control algorithm for the drives [1]. Adaptive control provides a promising manner to cope with parameter variations, in particular key parameter changes. However, adaptive control performance may be significantly degraded by disturbance or unmodeled dynamics. Furthermore, there may be multiple parameter variations in PMSM drives. The development of adaptive laws for multiple parameter adaptation make the controller complicated for implementation.

- DUEA: In the context of DUEA, a flexible manner to improve robustness and disturbance rejection performance in PMSM drives is to combine disturbances and uncertainties together for estimation. The estimate of disturbances/uncertainties is employed for feedforward compensation [4]. The DUEA approach achieves good servo control performance around the nominal operation condition but also satisfactory speed regulation performance in the presence of strong disturbances/uncertainties.

Based on the above analysis, the servo control performance of DUEA, robust control and adaptive control for PMSM drives are shown by Fig. 7 .

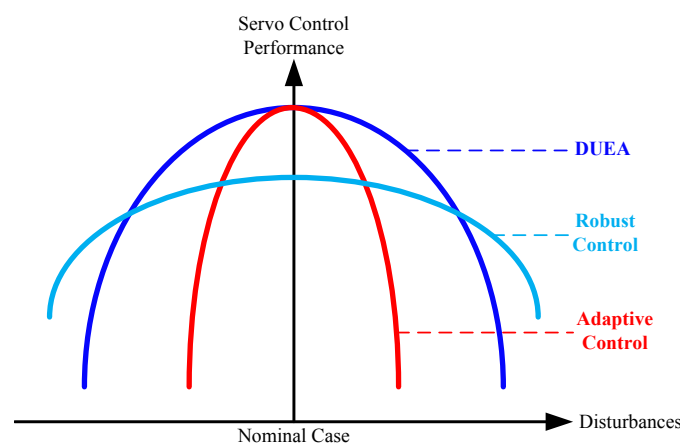

Fig. 7. Diagram of control performance of DUEA, robust control and adaptive control in PMSM drives.

So far there still lacks of comprehensive and fair comparison between these control methods on a well defined benchmark. 
Partially this is because adaptive control and robust control mainly focus on handling uncertainty, but DUEA deals with uncertainty and disturbance together. Comprehensive and fair comparison would be an area of much interests for both academic research and practical applications.

\section{B. DOBC Versus IMC}

As the internal model of a dynamic system is also embedded in the IMC design as in DOBC, it is interesting to discuss their similarities and differences. A complete IMC structure shown in Fig. 6, rather than a classic simple IMC structure, is adopted from [39] to facilitate the discussion. At a first glance, comparing Fig. 1 and Fig. 6 shows that these two control structures are quite similar. It shall be noted that adding a reference model to DOBC is straightforward as shown in a number of papers (e.g. [83]) if required for improving tracking performance. More notably, both these two schemes have an explicit internal model of the physical plant in the loop, a filter and a feedback controller. The reason for developing both these two schemes is also similar, i.e. improving disturbance rejection and robustness without sacrificing tracking performance.

However, carefully examining these two schemes reveal$\mathrm{s}$ subtle but important difference. The feedback signal for the closed-loop controller $C(s)$ is different. The difference between the output of the real plant and its model is fed back in IMC while, as in most of feedback systems, the output of the physical system is fed back in DOBC. This has significant implication in control system design and implementation. In IMC, if there is no mismatching between the physical system and its model, and the system is not subject to disturbance, the feedback loop is not activated. The system operates in an open-loop fashion so the alternation of the controlled dynamics mainly relies on the reference model (and the controller $C(s)$ ), which may cause problems in achieving satisfactory performance for some systems such as systems with unstable dynamics. In contrast, in the absence of disturbance and mismatching between the plant and its model, DOBC now reduces to a typical single degree of freedom feedback control system. Therefore all the existing control methods could be applied to design a closed-loop system to achieve stability and satisfactory performance. Furthermore, in IMC, the disturbance is equivalent to the output whereas all the disturbance and uncertainty is equivalent to the control input in all the classic DOBC schemes. In other words, the IMC structure is better in dealing with output disturbance while the DOBC structure is more suitable for handling input disturbance.

\section{DOBC Versus NOR}

The nonlinear output regulation (NOR) theory provides an elegant and rigorous framework in handling the tracking and disturbance compensation problem of nonlinear systems subject to disturbances generated by exogenous systems [40]. The objective of both DOBC and NOR are similar, that is, to achieve zero tracking errors in the presence of disturbances (and uncertainties). The basic principle in NOR is that, similar to the internal model principle for linear systems [84], a feedforward input term is generated to cancel the influence of disturbance by embedding the disturbance model in the loop. The central manifold plays a core role in NOR, and asymptotic disturbance rejection depends on the existence of an invariant manifold. Due to this specific reason, there are a number of differences between nonlinear DOBC and NOR.

- Complexity of Design: In the context of NOR, the solutions of coupled partial differential equations (PDEs) are involved in the controller/compensator synthesis. Solvability of such a set of PDEs have been rigorously investigated, however, despite all the efforts, solving these PDEs is still not easy for general nonlinear systems. There is a simple PDE involved in calculating the observer gain in DOBC for nonlinear systems, which is much easy to solve; a systematic method for solving it has been proposed (for example, [73]).

- Uncertainty Attenuation: The approaches on uncertainty attenuation in DOBC and NOR are different. In the context of NOR, only the external disturbances are compensated while the model uncertainties have to be suppressed by feedback control action. As for DOBC, both the external disturbances and model uncertainties are lumped together for estimation and final compensation. The tasks of feedback control and compensation control in DOBC are quite transparent, where the feedback control is used for tracking and stabilization while the compensation control acts like an added-on "patch" to enhance robustness against disturbances/uncertainties.

- Flexibility of Structure: In NOR, the controller and the disturbance compensation are designed by solving two PDE equations simultaneously. Similar to other DUEA, the DOBC structure allows one to design a controller and a disturbance observer independently and then integrate them together. This provides the flexibility of combining different controller (e.g. PID, linear quadratic regulator, model predictive control, and sliding mode control) and different disturbance observer (e.g. DOB, ESO, unknown input observer) design methods together. This property is very attractive since it enables the development of a more suitable composite controller tailored for a specific application. It also allows to adding the disturbance/uncertainty compensation loop directly on an existing control system to improve its disturbance rejection and/or robustness.

A brief comparison on advantages and disadvantages of DUEA and related methods is summarized as shown in Table III.

\section{Applications of DUEA in AC Machine Drives}

In this section, we will further discuss the practical applications and industrialization issues of DUEA in AC machine drives. A systematic overview on typical utilizations of disturbance observation techniques, manners of combination with advanced feedback control, and commercialization and industrialization of DUEA approaches in AC machine drives is provided as follows. 
TABLE III

Comparisons of DUEA and Related Methods in AC Machine Drives

\begin{tabular}{cllc}
\hline Methods & \multicolumn{1}{c}{ Advantages } & \multicolumn{1}{c}{ Disadvantages } & Applications \\
\hline $\begin{array}{c}\text { Robust } \\
\text { Control }\end{array}$ & $\begin{array}{l}\text { strong robustness (in particular in the } \\
\text { worst case); conceptual intuitive and } \\
\text { straightforward for implementation }\end{array}$ & $\begin{array}{l}\text { robustness is achieved at a price of } \\
\text { sacrificing nominal control performance }\end{array}$ & {$[11,13]$} \\
\hline $\begin{array}{c}\text { Adaptive } \\
\text { Control }\end{array}$ & $\begin{array}{l}\text { strong adaptiveness against severe } \\
\text { parameter uncertainty, for example, } \\
\text { inertial variation in AC motor }\end{array}$ & $\begin{array}{l}\text { sensitive to structural uncertainties such } \\
\text { as unmodelled dynamics and complex } \\
\text { disturbances }\end{array}$ & {$[14-18]$} \\
\hline $\begin{array}{c}\text { Output } \\
\text { Regulation }\end{array}$ & $\begin{array}{l}\text { fully exploiting disturbance model for } \\
\text { control design; expected higher } \\
\text { disturbance rejection performance }\end{array}$ & $\begin{array}{l}\text { structure not flexible; complex for } \\
\text { implementation }\end{array}$ & {$[2,21]$} \\
\hline IMC & $\begin{array}{l}\text { simple control structure; 2-degree of } \\
\text { freedom design for tracking and } \\
\text { disturbance rejection }\end{array}$ & $\begin{array}{l}\text { limited control performance in the } \\
\text { presence of complex disturbances }\end{array}$ & {$[20]$} \\
\hline \multirow{2}{*}{ DUEA } & $\begin{array}{l}\text { conceptual intuitive; good balance } \\
\text { among performances; different } \\
\text { disturbance types }\end{array}$ & $\begin{array}{l}\text { extra efforts required to explore the } \\
\text { features of disturbances for appropriate } \\
\text { choices of DUEA methods }\end{array}$ & {$[27-32]$} \\
\hline
\end{tabular}

\section{A. Typical Utilizations of Disturbance Observations}

The aforementioned disturbance observation techniques have been intensively applied to estimate disturbances and uncertainties including load torque, torque ripple, variation of inertia, frictions, etc., in AC servo systems such as PMSM, IM and BLDCM. The typical utilizations are summarized as follows:

1) Load Torque Observer: The recovery performance after turbulence of a sudden load variation is one of the most important performance specification in AC servo system. One of the early motivations on developing DOB was to design an online load toque observer in motor drives. Recently, disturbance observation techniques have been extensively investigated as load toque observation, for example, see DOB [23], [24], [32], [85]-[88], ESO [12], [33], [36], [89], generalized proportional integral observer (GPIO) [90], [91], sliding mode disturbance observer (SMDO) [92] and intelligent disturbance observer (IDO) [70], [93], [94] for PMSM ( [12], [23], [24], [32], [33], [36], [92]), IM ( [85], [86], [89]-[91], [93], [94]) and BLDCM ( [87], [88]), respectively.

2) Inertia Identification: In some applications, e.g., welding robots, or transfer robots with heavy loads, the inertia increases to more than several times of the original inertia, and the large mismatch between the plant and model will result in severe degradations of closed-loop control performance. Disturbance observation techniques provide an adequate way for inertia identification and adaptive control of PMSM systems, see [18], [20], [79].

3) Friction Compensator: The effect of friction is a dominant consideration in $\mathrm{AC}$ servo systems. The presence of various frictions always cause undesirable influences on control precision improvement. Based on the fundamental friction models, friction estimators and compensation are generally utilized for high precision servo control of AC motors such as PMSM [17], [18], [26], [34] and IM [90].

4) Torque Ripple Estimator: The torque ripple is a crucial disturbance caused by the distortion of the cogging effect, stator flux linkage distribution, and current measurement errors, which results in great performance degradation of AC servo systems. By incorporating the internal model of disturbance ripples in the observer design, various torque ripple estimators have been proposed for PMSM systems [2], [4], [21], [29], [30]. In [48], disturbance observation technique is used to estimate the torque ripple caused by back-EMF of BLDCM.

5) Lumped Disturbance/Uncertainty Estimator: Since uncertainties in AC servo system could be treated as disturbances in the framework of DUEA, lumped disturbance/uncertainty estimator is also a very popular utilization due to its intuitive concept, straightforward design and implementation. For this kind of applications, see DOB [5], [25], [28], [31], [95], SMDO [96], ESO [35], [89], [97], [98], GPIO [90], [91] and IDO [93], [94] applied to PMSM ( [5], [25], [28], [35], [96]), IM ( [89]-[91], [93], [94]), BLDCM ( [95], [97]) and switching reluctance motor ( [98]) to name but just a few.

In practical engineering, dominant disturbances vary depending on the application areas of the AC servo system. In addition, the servo system is usually subject to multiple disturbances rather than single one. Combination of load toque observer, inertial identification, friction compensator and torque ripple estimator should be conducted for the controller to handle multiple sources of disturbances and uncertainties [18], [31].

\section{B. Manners of Combination With Advanced Feedback Control}

From the point view of control design, the disturbance observation techniques can be flexibly incorporated with various feedback control approaches including PID control [18], [26], [33]-[35], adaptive and robust control [17], nonlinear control [23], [25], [96], model predictive control [5], [12], sliding mode control [24], [28], [36], [92], neural network controller [99] and fuzzy logic controller [70] for difference purposes. For instance, disturbance estimators are combined with adaptive and robust control to further enhance adaptiveness and robustness of servo systems [17]. In [24], [36], [92], the disturbance observation techniques are employed to reduce the control chattering problem existing in traditional sliding mode control approaches. 
TABLE IV

COMPARISONS OF DifFERENT DUEA METHOdS IN AC MACHINE DRIVES

\begin{tabular}{|c|c|c|c|c|c|c|c|c|}
\hline \multirow{2}{*}{$\begin{array}{l}\text { DUEA } \\
\text { Methods }\end{array}$} & \multicolumn{2}{|c|}{ Complexity } & \multicolumn{5}{|c|}{ Capability } & \multirow[b]{2}{*}{$\begin{array}{l}\text { Used In } \\
\text { Product }\end{array}$} \\
\hline & $\begin{array}{l}\text { Output } \\
\text { Feedback }\end{array}$ & $\begin{array}{c}\text { Computation } \\
\text { Burdern }\end{array}$ & $\begin{array}{c}\text { Load Torque } \\
\text { Observer }\end{array}$ & \begin{tabular}{|c|} 
Inertial \\
Identification
\end{tabular} & $\begin{array}{c}\text { Friction } \\
\text { Compensation }\end{array}$ & $\begin{array}{c}\text { Torque Ripple } \\
\text { Estimator }\end{array}$ & \begin{tabular}{|c|} 
Lumped \\
Estimator
\end{tabular} & \\
\hline ADRC & $\sqrt{ }$ & Low & $\sqrt{ }$ & $x$ & $x$ & $x$ & $\sqrt{ }$ & $\sqrt{ }$ \\
\hline EIDBC & Possible & Medium & $\sqrt{ }$ & $x$ & Possible & $x$ & $\sqrt{ }$ & $x$ \\
\hline FDDOBC & $\sqrt{ }$ & Low & $\sqrt{ }$ & Possible & Possible & $x$ & $\sqrt{ }$ & $\sqrt{ }$ \\
\hline GPIOBC & $\sqrt{ }$ & Medium & $\sqrt{ }$ & $x$ & $x$ & $x$ & $\sqrt{ }$ & $x$ \\
\hline IDOBC & Possible & High & $\sqrt{ }$ & $\sqrt{ }$ & $\sqrt{ }$ & $\sqrt{ }$ & $\sqrt{ }$ & $x$ \\
\hline NDOBC & $x$ & High & $\sqrt{ }$ & $\sqrt{ }$ & $\sqrt{ }$ & $\sqrt{ }$ & $\sqrt{ }$ & $x$ \\
\hline SMDOBC & Possible & High & $\sqrt{ }$ & Possible & $\sqrt{ }$ & $\sqrt{ }$ & $\sqrt{ }$ & $x$ \\
\hline UDEBC & $x$ & Medium & $\sqrt{ }$ & $x$ & Possible & $x$ & $\sqrt{ }$ & $x$ \\
\hline UIOBC & Possible & Medium & $\sqrt{ }$ & Possible & Possible & $\sqrt{ }$ & $\sqrt{ }$ & $x$ \\
\hline
\end{tabular}

\section{Commercialization and Industrialization}

In addition to numerous academic achievements on DUEA approaches, compared with other advanced control methods, one significant feature of DUEA is its large-scale commercialization and industrialization in AC servo systems. It has been embedded in a number of servo and drive products in the market. For instance, DOBC techniques have been embedded in the products of Panasonic MINAS A5-series AC servo motors and drives for a variety of purposes including torque observation and compensation [100]. ADRC approach has been utilized in the products of Estun EDC-08 APE and EDB-10 AMA series AC servo drives for inertia moment identification and disturbance/uncertainty attenuation [101].

The differences among different DUEA methods in AC machine drives are comparatively summarized and explicitly shown in Table IV.

\section{CONCLUSions AND PRospects}

\section{A. Concluding Remarks}

This paper has provided a systematic overview of disturbances/uncertainties in PMSM drives, and also DUEA and other relevant methods in handling disturbances and uncertainties for PMSM systems. More importantly, it has been argued in this paper that DUEA method has provided an alternative to robust control and adaptive control, and complementary to them in the field of PMSM drives. The similarities and differences between DOBC (particularly NDOBC) and two other well known methods widely applied in dealing with disturbances in AC motor drives, namely IMC and NOR, have been provided. As there is a wealth of theoretic tools and methods in these well established control methods, understanding these relationships makes it possible to improve theoretic studies in DUEA and other relevant advanced control methods for improving disturbance attenuation and robustness of $\mathrm{AC}$ servo systems.

\section{B. Open Issues}

In spite of significant progress has been made for DUEA techniques in AC machine drives, there are still many open issues to be addressed in the future:
1) Disturbance/Uncertainty Modeling: The models of disturbance/uncertainty are generally employed in DUEA approaches, albeit they actually do not rely on precise models. More information of the disturbance/uncertainty utilized in the controller will be definitely helpful for performance improvements. Consequently, a promising future direction is to develop new tools for more accurate disturbance/uncertainty modeling in $\mathrm{AC}$ machine drives.

2) Multiple Disturbance Attenuation: The AC machine drives are generally subject to multiple disturbances and uncertainties rather than a single one. Combination of different DUEA approaches together provides a promising manner to handle this problem. However, rigorous performance analysis is difficult, and furthermore how to integrate different DUEAs together is not easy. As such, design and synthesis of DUEA techniques for AC machine drives under multiple disturbance/uncertainty is also an open issue to be addressed.

3) Constraint Handling: Quite often, there are various constraints on the physical variables/parameters in AC machine drives. Most DUEA approaches have not considered those issues, however, violating the constraints would degrade performance even compromise safety of AC servo control systems. New tools and techniques [102] on constraint handling are interesting and imperative for application of DUEA in AC machine drives.

4) Condition Monitoring: Machine vibration analysis and motor current spectral analysis (MCSA) have been widely used for abnormal condition monitoring [103], [104]. Development of condition monitoring techniques is sometimes helpful for disturbance modeling. For example, making full use of the information obtained by MCSA is beneficial for disturbance modeling and estimation design. As such, combination condition monitoring with DUEA will further improve the servo control performance of machine drives in the practical application.

5) New Methods and Applications: With the fast development of machine drives and control theory, it expected that new DUEAs should be explored to meet the new 
requirement of new generation of $\mathrm{AC}$ machine drives. For instance, a control strategy called finite control set model predictive control has been proposed recently for motor drives and power electronics without resorting to the pulse-width modulating technique [105]. New DUEA approaches shall be investigated to integrate with this and other novel control strategies.

\section{REFERENCES}

[1] S. Li and Z. Liu, "Adaptive speed control for permanent-magnet synchronous motor system with variations of load inertia," IEEE Trans. Ind. Electron., vol. 56, no. 8, pp. 3050-3059, 2009.

[2] Y. A.-R. I. Mohamed and E. El-Saadany, "A current control scheme with an adaptive internal model for torque ripple minimization and robust current regulation in pmsm drive systems," IEEE Trans. Energy Convers., vol. 23, no. 1, pp. 92-100, 2008.

[3] N.-M. Babak, M.-T. Farid, and F.-M. Sargos, "Mechanical sensorless control of pmsm with online estimation of stator resistance," IEEE Trans. Ind. Appl., vol. 40, no. 2, pp. 457-471, 2004.

[4] Y. A.-R. I. Mohamed, "Design and implementation of a robust currentcontrol scheme for a pmsm vector drive with a simple adaptive disturbance observer," IEEE Trans. Ind. Electron., vol. 54, no. 4, pp. 1981-1988, 2007.

[5] R. Errouissi, M. Ouhrouche, W.-H. Chen, and A. Trzynadlowski, "Robust cascaded nonlinear predictive control of a permanent magnet synchronous motor with antiwindup compensator," IEEE Trans. Ind. Electron., vol. 59, no. 8, pp. 3078-3088, 2012.

[6] Z. Zhu, S. Ruangsinchaiwanich, and D. Howe, "Synthesis of coggingtorque waveform from analysis of a single stator slot," IEEE Trans. Ind. Appl., vol. 42, no. 3, pp. 650-657, 2006.

[7] W. Qian, S. Panda, and J.-X. Xu, "Torque ripple minimization in pm synchronous motors using iterative learning control," IEEE Trans. Power Electron., vol. 19, no. 2, pp. 272-279, 2004.

[8] S.-H. Hwang and J.-M. Kim, "Dead time compensation method for voltage-fed pwm inverter," IEEE Trans. Energy Convers., vol. 25, no. 1, pp. 1-10, 2010.

[9] D.-W. Chung and S.-K. Sul, "Analysis and compensation of current measurement error in vector-controlled ac motor drives," IEEE Trans. Ind. Appl., vol. 34, no. 2, pp. 340-345, 1998.

[10] S. Vukosavić and M. Stojić, "Suppression of torsional oscillations in a high-performance speed servo drive," IEEE Trans. Ind. Electron., vol. 45 , no. 1 , pp. 108-117, 1998.

[11] R. Errouissi, M. Ouhrouche, W.-H. Chen, and A. Trzynadlowski, "Robust nonlinear predictive controller for permanent-magnet synchronous motors with an optimized cost function," IEEE Trans. Ind. Electron., vol. 59, no. 7, pp. 2849-2858, 2012.

[12] H. Liu and S. Li, "Speed control for pmsm servo system using predictive functional control and extended state observer," IEEE Trans. Ind. Electron., vol. 59, no. 2, pp. 1171-1183, 2012.

[13] F. El-Sousy, "Hybrid $h \infty$-based wavelet-neural-network tracking control for permanent-magnet synchronous motor servo drives," IEEE Trans. Ind. Electron., vol. 57, no. 9, pp. 3157-3166, 2010.

[14] H. Chaoui and P. Sicard, "Adaptive fuzzy logic control of permanent magnet synchronous machines with nonlinear friction," IEEE Trans. Ind. Electron., vol. 59, no. 2, pp. 1123-1133, 2012.

[15] M. Morawiec, "The adaptive backstepping control of permanent magnet synchronous motor supplied by current source inverter," IEEE Trans. Ind. Inform., vol. 9, no. 2, pp. 1047-1055, 2013.

[16] H. Choi, N. T.-T. Vu, and J.-W. Jung, "Digital implementation of an adaptive speed regulator for a pmsm," IEEE Trans. Power Electron., vol. 26, no. 1, pp. 3-8, 2011.

[17] J. Na, Q. Chen, X. Ren, and Y. Guo, "Adaptive prescribed performance motion control of servo mechanisms with friction compensation," IEEE Trans. Ind. Electron., vol. 61, no. 1, pp. 486-494, 2014.

[18] R. Garrido and A. Concha, "Inertia and friction estimation of a velocity-controlled servo using position measurements," IEEE Trans. Ind. Electron., vol. 61, no. 9, pp. 4759-4770, 2014.

[19] V. Hernández-Guzmán and R. Silva-Ortigoza, "Pi control plus electric current loops for pm synchronous motors," IEEE Trans. Control Syst. Technol., vol. 19, no. 4, pp. 868-873, 2011.

[20] S. Li and H. Gu, "Fuzzy adaptive internal model control schemes for pmsm speed-regulation system," IEEE Trans. Ind. Inform., vol. 8, no. 4, pp. 767-779, 2012.
[21] W.-C. Gan and L. Qiu, "Torque and velocity ripple elimination of ac permanent magnet motor control systems using the internal model principle," IEEE-ASME Trans. Mechatron., vol. 9, no. 2, pp. 436-447, 2004.

[22] E. Sariyildiz and K. Ohnishi, "Stability and robustness of disturbanceobserver-based motion control systems," IEEE Trans. Ind. Electron., vol. 62, no. 1, pp. 414-422, 2015.

[23] H. Jin and J. Lee, "An rmrac current regulator for permanent-magnet synchronous motor based on statistical model interpretation," IEEE Trans. Ind. Electron., vol. 56, no. 1, pp. 169-177, 2009.

[24] S. Li, M. Zhou, and X. Yu, "Design and implementation of terminal sliding mode control method for pmsm speed regulation system," IEEE Trans. Ind. Inform., vol. 9, no. 4, pp. 1879-1891, 2013.

[25] M. Khanchoul, M. Hilairet, and D. Normand-Cyrot, "A passivity-based controller under low sampling for speed control of pmsm," Control Eng. Practice, vol. 26, pp. 20-27, 2014.

[26] Z. Jamaludin, H. Van Brussel, and J. Swevers, "Friction compensation of an $x y$ feed table using friction-model-based feedforward and an inverse-model-based disturbance observer," IEEE Trans. Ind. Electron., vol. 56, no. 10, pp. 3848-3853, 2009.

[27] Y.-R. Mohamed, "A hybrid-type variable-structure instantaneous torque control with a robust adaptive torque observer for a high-performance direct-drive pmsm," IEEE Trans. Ind. Electron., vol. 54, no. 5, pp. 2491-2499, 2007.

[28] V. Leu, H. Choi, and J.-W. Jung, "Fuzzy sliding mode speed controller for pm synchronous motors with a load torque observer," IEEE Trans. Power Electron., vol. 27, no. 3, pp. 1530-1539, 2012.

[29] H.-W. Kim, M.-J. Youn, K.-Y. Cho, and H.-S. Kim, "Nonlinearity estimation and compensation of pwm vsi for pmsm under resistance and flux linkage uncertainty," IEEE Trans. Control Syst. Technol., vol. 14, no. 4, pp. 589-601, 2006.

[30] W. Kim, D. Shin, and C. Chung, "Microstepping using a disturbance observer and a variable structure controller for permanent-magnet stepper motors," IEEE Trans. Ind. Electron., vol. 60, no. 7, pp. 2689 2699, 2013.

[31] C. De Angelo, G. Bossio, J. Solsona, G. García, and M. Valla, "Mechanical sensorless speed control of permanent-magnet ac motors driving an unknown load," IEEE Trans. Ind. Electron., vol. 53, no. 2, pp. 406-414, 2006.

[32] J. Solsona, M. Valla, and C. Muravchik, "Nonlinear control of a permanent magnet synchronous motor with disturbance torque estimation," IEEE Trans. Energy Convers., vol. 15, no. 2, pp. 163-168, 2000.

[33] S. Li, C. Xia, and X. Zhou, "Disturbance rejection control method for permanent magnet synchronous motor speed-regulation system," Mechatronics, vol. 22, no. 6, pp. 706-714, 2012.

[34] M. Sun, Z. Wang, Y. Wang, and Z. Chen, "On low-velocity compensation of brushless dc servo in the absence of friction model," IEEE Trans. Ind. Electron., vol. 60, no. 9, pp. 3897-3905, 2013.

[35] Y. Su, C. Zheng, and B. Duan, "Automatic disturbances rejection controller for precise motion control of permanent-magnet synchronous motors," IEEE Trans. Ind. Electron., vol. 52, no. 3, pp. 814-823, 2005.

[36] S. Li, K. Zong, and H. Liu, "A composite speed controller based on a second-order model of permanent magnet synchronous motor system," Trans. Inst. Meas. Control, vol. 33, no. 5, pp. 522-541, 2011.

[37] W.-H. Chen, J. Yang, L. Guo, and S. Li, "Disturbance observer-based control and related methods-an overview," IEEE Trans. Ind. Electron., vol. Published Online, 2015.

[38] S. Li, J. Yang, W.-H. Chen, and X. Chen, Disturbance Observer Based Control: Methods and Applications. CRC Press, Florida, USA, 2014.

[39] C. Garcia and M. Morari, "Internal model control-I: a unifying review and some new results," Ind. Eng. Chem. Process Des. Dev., vol. 21, no. 2 , pp. 308-323, 1982.

[40] A. Isidori and C. Byrnes, "Output regulation of nonlinear systems," IEEE Trans. Autom. Control, vol. 35, no. 2, pp. 131-140, 1990.

[41] G. Stelmach, Motor control: Issues and Trends. Academic Press, 2014.

[42] T. Jahns and W. Soong, "Pulsating torque minimization techniques for permanent magnet ac motor drives-a review," IEEE Trans. Ind. Electron., vol. 43, no. 2, pp. 321-330, 1996.

[43] P. Dziwniel, B. Boualem, F. Piriou, J. Ducreux, and P. Thomas, "Comparison between two approaches to model induction machines with skewed slots," IEEE Trans. Magn., vol. 36, no. 4, pp. 1453-1457, 2000.

[44] T. Sebastian, "Temperature effects on torque production and efficiency of pm motors using ndfeb magnets," IEEE Trans. Ind. Appl., vol. 31, no. 2, pp. 353-357, 1995. 
[45] S.-K. Chung, H.-S. Kim, C.-G. Kim, and M.-J. Youn, "A new instantaneous torque control of pm synchronous motor for high-performance direct-drive applications," IEEE Trans. Power Electron., vol. 13, no. 3, pp. 388-400, 1998.

[46] C. Xia, Y. Wang, and T. Shi, "Implementation of finite-state model predictive control for commutation torque ripple minimization of permanent-magnet brushless dc motor," IEEE Trans. Ind. Electron. vol. 60, no. 3, pp. 896-905, 2013.

[47] J. Shi and T. Li, "New method to eliminate commutation torque ripple of brushless dc motor with minimum commutation time," IEEE Trans. Ind. Electron., vol. 60, no. 6, pp. 2139-2146, 2013.

[48] C. Xia, Y. Xiao, W. Chen, and T. Shi, "Torque ripple reduction in brushless dc drives based on reference current optimization using integral variable structure control," IEEE Trans. Ind. Electron., vol. 61, no. 2, pp. 738-752, 2014.

[49] J. Fang, H. Li, and B. Han, "Torque ripple reduction in bldc torque motor with nonideal back emf," IEEE Trans. Ind. Electron., vol. 27, no. 11, pp. 4630-4637, 2012.

[50] T. Sheng, X. Wang, J. Zhang, and Z. Deng, "Torque-ripple mitigation for brushless dc machine drive system using one-cycle average torque control," IEEE Trans. Ind. Electron., vol. 62, no. 4, pp. 2114-2122, 2015.

[51] S.-Y. Kim, W. Lee, M.-S. Rho, and S.-Y. Park, "Effective dead-time compensation using a simple vectorial disturbance estimator in pmsm drives," IEEE Trans. Ind. Electron., vol. 57, no. 5, pp. 1609-1614, 2010.

[52] N. Urasaki, T. Senjyu, K. Uezato, and T. Funabashi, "An adaptive dead-time compensation strategy for voltage source inverter fed motor drives," IEEE Trans. Power Electron., vol. 20, no. 5, pp. 1150-1160, 2005.

[53] J. Shi and S. Li, "Analysis and compensation control of dead-time effect on space vector pwm," J. Power Electron., vol. 15, no. 2, pp. 431-442, 2015.

[54] A. Boglietti, A. Cavagnino, and D. Staton, "Determination of critical parameters in electrical machine thermal models," IEEE Trans. Ind. Appl., vol. 44, no. 4, pp. 1150-1159, 2008.

[55] A. El-Refaie, N. Harris, T. Jahns, and K. Rahman, "Thermal analysis of multibarrier interior pm synchronous machine using lumped parameter model," IEEE Trans. Energy Convers., vol. 19, no. 2, pp. 303-309, 2004.

[56] M. Rashed, P. MacConnell, A. Stronach, and P. Acarnley, "Sensorless indirect-rotor-field-orientation speed control of a permanent-magnet synchronous motor with stator-resistance estimation," IEEE Trans. Ind. Electron., vol. 54, no. 3, pp. 1664-1675, 2007.

[57] M. Gyimesi and D. Ostergaard, "Inductance computation by incremental finite element analysis," IEEE Trans. Magn., vol. 35, no. 3, pp. 1119-1122, 1999.

[58] K. Meessen, P. Thelin, J. Soulard, and E. Lomonova, "Inductance calculations of permanent-magnet synchronous machines including flux change and self-and cross-saturations," IEEE Trans. Magn., vol. 44, no. 10 , pp. 2324-2331, 2008.

[59] H. Olsson, K. Åström, C. Canudas de Wit, M. Gäfvert, and P. Lischinsky, "Friction models and friction compensation," Eur. J. Control, vol. 4, no. 3, pp. 176-195, 1998.

[60] C. Canudas de Wit and P. Lischinsky, "Adaptive friction compensation with partially known dynamic friction model," Int. J. Adapt. Control Signal Process., vol. 11, no. 1, pp. 65-80, 1997.

[61] W. Carter, "Mechanical factors affecting electrical drive performance," IEEE Trans. Ind. Gen Appl., no. 3, pp. 282-290, 1969.

[62] S. Bognatz, "Alignment of critical and non critical machines," Orbit, vol. 4, pp. 23-25, 1995.

[63] K. Ohishi, M. Nakao, K. Ohnishi, and K. Miyachi, "Microprocessorcontrolled DC motor for load-insensitive position servo system," IEEE Trans. Ind. Electron., vol. 34, no. 1, pp. 44-49, 1987.

[64] J. Han, "Extended state observer for a class of uncertain plants," Control and Decision, vol. 10, no. 1, pp. 85-88, 1995 (in Chinese).

[65] C. Johnson, "Optimal control of the linear regulator with constant disturbances," IEEE Trans. Autom. Control, vol. 13, no. 4, pp. 416-421, 1968.

[66] M. Fliess, R. Marquez, E. Delaleau, and H. Sira-Ramirez, "Generalized proportional-integral controllers," ESAIM: Control, Optimization and Calculus of Variations, vol. 7, pp. 23-41, 2002.

[67] J.-H. She, M. Fang, Y. Ohyama, H. Hashimoto, and M. Wu, "Improving disturbance-rejection performance based on an equivalent-inputdisturbance approach," IEEE Trans. Ind. Electron., vol. 55, no. 1, pp. 380-389, 2008.
[68] Q.-C. Zhong, A. Kuperman, and R.-K. Stobart, "Design of UDE-based controllers from their two-degree-of-freedom nature," Int. J. Robust Nonlinear Control, vol. 17, no. 21, pp. 1994-2008, 2011.

[69] A. Levant, "Higher-order sliding modes, differentiation and outputfeedback control," Int. J. Control, vol. 76, no. 9/10, pp. 924-941, 2003.

[70] H. Choi, N. T.-T. Vu, and J.-W. Jung, "Design and implementation of a takagi-sugeno fuzzy speed regulator for a permanent magnet synchronous motor,' IEEE Trans. Ind. Electron., vol. 59, no. 8, pp. 3069-3077, 2012

[71] T. Umeno, T. Kaneko, and Y. Hori, "Robust servosystem design with two degrees of freedom and its application to novel motion control of robot manipulators," IEEE Trans. Ind. Electron., vol. 40, no. 5, pp. 473-485, 1993.

[72] S. Shahruz, "Performance enhancement of a class of nonlinear systems by disturbance observers," IEEE-ASME Trans. Mechatron., vol. 5, no. 3, pp. 319-323, 2000

[73] W.-H. Chen, "Disturbance observer based control for nonlinear systems," IEEE-ASME Trans. Mechatron., vol. 9, no. 4, pp. 706-710, 2004.

[74] W.-H. Chen, D. Ballance, P. Gawthrop, and J. O'Reilly, "A nonlinear disturbance observer for robotic manipulators," IEEE Trans. Ind. Electron., vol. 47, no. 4, pp. 932-938, 2000.

[75] J. Han, "From PID to active disturbance rejection control," IEEE Trans. Ind. Electron., vol. 56, no. 3, pp. 900-906, 2009.

[76] Y. Huang and W. Xue, "Active disturbance rejection control: methodology and theoretical analysis," ISA Trans., vol. 53, no. 4, pp. 963-976, 2014.

[77] B. Bose, "Power electronics and motor drives recent progress and perspective," IEEE Trans. Ind. Electron., vol. 56, no. 2, pp. 581-588, 2009.

[78] Y.-S. Kung and M.-H. Tsai, "Fpga-based speed control ic for pmsm drive with adaptive fuzzy control," IEEE Trans. Power Electron., vol. 22, no. 6, pp. 2476-2486, 2007.

[79] S. Li and Z. Liu, "Adaptive speed control for permanent magnet synchronous motor system with variations of load inertia," IEEE Trans. Ind. Electron., vol. 56, no. 8, pp. 3050-3059, 2009.

[80] J. Huang, Nonlinear Output Regulation. Philadelphia: SIAM, 2004.

[81] K. Zhou and J. Doyle, Essentials of robust control. Prentice Hall, 1998.

[82] C. Johnson, "Adaptive controller design using disturbanceaccommodation techniques," Int. J. Control, vol. 42, no. 1, pp. 193-210, 1985.

[83] W.-H. Chen, "Nonlinear disturbance observer-enhanced dynamic inversion control of missiles," Journal of Guidance, Control and Dynamics, vol. 26, no. 1, pp. 161-166, 2003.

[84] B. Francis and W. Wonham, "The internal model principle of control theory," Automatica, vol. 12, no. 5, pp. 457-465, 1976.

[85] B. Veselić, B. Peruničić-Draženović, and Č. Milosavljević, "Highperformance position control of induction motor using discrete-time sliding-mode control," IEEE Trans. Ind. Electron., vol. 55, no. 11, pp. 3809-3817, 2008.

[86] A. Merabet, M. Ouhrouche, and R.-T. Bui, "Nonlinear predictive control with disturbance observer for induction motor drive," in 2006 IEEE International Symposium on Industrial Electronics, vol. 1. IEEE, 2006, pp. 86-91.

[87] A. Stirban, I. Boldea, and G.-D. Andreescu, "Motion-sensorless control of bldc-pm motor with offline fem-information-assisted position and speed observer," IEEE Trans. Ind. Appl., vol. 48, no. 6, pp. 1950-1958, 2012.

[88] J. Ko, J. Lee, S. Chung, and M. Youn, "A robust digital position control of brushless dc motor with dead beat load torque observer," IEEE Trans. Ind. Electron., vol. 40, no. 5, pp. 512-520, 1993.

[89] G. Feng, Y.-F. Liu, and L. Huang, "A new robust algorithm to improve the dynamic performance on the speed control of induction motor drive," IEEE Trans. Power Electron., vol. 19, no. 6, pp. 1614-1627, 2004.

[90] H. Sira-Ramírez, F. Gonzalez-Montanez, J. Cortés-Romero, and A. Luviano-Juárez, "A robust linear field-oriented voltage control for the induction motor: experimental results," IEEE Trans. Ind. Electron., vol. 60, no. 8, pp. 3025-3033, 2013.

[91] J. Cortés-Romero, A. Luviano-Juárez, and H. Sira-Ramírez, "Robust gpi controller for trajectory tracking for induction motors," in 2009 IEEE International Conference on Mechatronics. IEEE, 2009, pp. $1-6$.

[92] X. Zhang, L. Sun, K. Zhao, and L. Sun, "Nonlinear speed control for pmsm system using sliding-mode control and disturbance compensation techniques," IEEE Trans. Power Electron., vol. 28, no. 3, pp. 1358-1365, 2013. 
[93] K.-B. Lee, S.-H. Huh, J.-Y. Yoo, and F. Blaabjerg, "Performance improvement of dtc for induction motor-fed by three-level inverter with an uncertainty observer using rbfn," IEEE Trans. Energy Convers., vol. 20, no. 2, pp. 276-283, 2005.

[94] K.-B. Lee and F. Blaabjerg, "Improved sensorless vector control for induction motor drives fed by a matrix converter using nonlinear modeling and disturbance observer," IEEE Trans. Energy Convers., vol. 21, no. 1, pp. 52-59, 2006

[95] M. Tomita, T. Senjyu, S. Doki, and S. Okuma, "New sensorless control for brushless dc motors using disturbance observers and adaptive velocity estimations," IEEE Trans. Ind. Electron., vol. 45, no. 2, pp. 274-282, 1998.

[96] G. Sun, X. Ren, and D. Li, "Neural active disturbance rejection output control of multimotor servomechanism," IEEE Trans. Control Syst. Technol., vol. 23, no. 2, pp. 746-753, 2015.

[97] X. Chang, Y. Li, W. Zhang, N. Wang, and W. Xue, "Active disturbance rejection control for a flywheel energy storage system," IEEE Trans. Ind. Electron., vol. 62, no. 2, pp. 991-1001, 2015.

[98] J. Pan, N. Cheung, and J. Yang, "Auto-disturbance rejection controller for novel planar switched reluctance motor," IET Electr. Power Appl., vol. 153, no. 2, pp. 307-316, 2006.

[99] J. Li, S. Li, and X. Chen, "Adaptive speed control of a pmsm servo system using an rbfn disturbance observer," Trans. Inst. Meas. Control, vol. 34 , no. 5, pp. 615-626, 2012

[100] Panasonic, Operating Instructions (Overall), AC Servo Motor \& Driver MINAS A5-series, 2009.

[101] www.estun.com/product/jiao-liu-si-fu-xi-tong-ji-yun-dong-kong-zhijie-jue-fang-an/si-fu-qu-dong/edbedc-xi-lie-si-fu-qu-dong-qi.

[102] T. Tarczewski and L. Grzesiak, "Constrained state feedback speed control of pmsm based on model predictive approach," IEEE Trans. Ind. Electron., vol. Published Online, 2015

[103] S. Nandi, H. Toliyat, and X. Li, "Condition monitoring and fault diagnosis of electrical motors-a review," IEEE Trans. Energy Convers., vol. 20, no. 4, pp. 719-729, 2005.

[104] R. R. Schoen, T. G. Habetler, F. Kamran, and R. Bartfield, "Motor bearing damage detection using stator current monitoring," IEEE Trans. Ind. Appl., vol. 31, no. 6, pp. 1274-1279, 1995.

[105] L. Wang, S. Chai, D. Yoo, L. Gan, and K. Ng, PID and Predictive Control of Electrical Drives and Power Converters using MATLAB/Simulink. Wiley-IEEE Press, 2014.

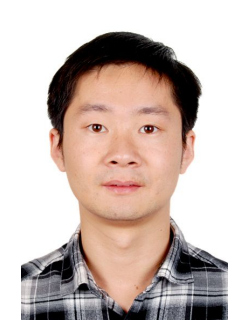

Jun Yang (M'11) was born in Anlu, Hubei Province, China in 1984. He received his B.Sc. degree in the Department of Automatic Control from Northeastern University, Shenyang, China in 2006. In 2011, he received his Ph.D. degree in control theory and control engineering from School of Automation, Southeast University, Nanjing, China, where he is currently an Associate Professor. He once visited Loughborough University in UK, University of Western Sydney in Australia and RMIT University in Australia as Visiting Scholars in 2009, 2013 and 2014, respectively. His research interests include disturbance estimation and compensation, advanced control theory and its application to flight control systems and motion control systems. He served as a guest editor of Transactions of the Institute of Measurement and Control. He is a member of IEEE.

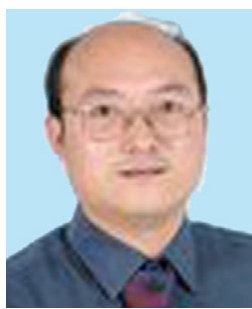

Wen-Hua Chen (SM'06) received the M.Sc. and $\mathrm{Ph} . \mathrm{D}$. degrees from Northeast University, Shenyang China, in 1989 and 1991, respectively.

From 1991 to 1996, he was a Lecturer and then Associate Professor with the Department of Automatic Control, Nanjing University of Aeronautics and Astronautics, Nanjing, China. From 1997 to 2000 , he held a research position and then a Lecturer in control engineering with the Centre for Systems and Control, University of Glasgow, Glasgow, UK. In 2000, he moved to the Department of Aeronautical and Automotive Engineering, Loughborough University, Loughborough, UK, as a Lecturer, where he was appointed as a Professor in 2012. His research interests include the development of advanced control strategies (Nonlinear Model Predictive Control, Disturbance Observer Based Control, etc.) and their applications in aerospace and automotive engineering. Currently, much of his work has also involved in the development of Unmanned Autonomous Intelligent Systems.

$\mathrm{He}$ is a Senior Member of IEEE and a Fellow of IET.

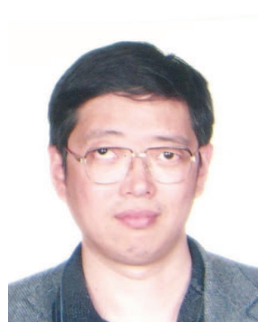

Lei Guo was born in Qufu, China, in 1966. He received his B.S. and M.S. degrees from Qufu Normal University (QFNU), China in 1988 and 1991, respectively and the Ph.D. degree in control engineering from Southeast University (SEU) in 1997.

From 1991 to 1994, he was with Qingdao University (QDU) as a lecturer. From 1997 to 1999 , he was a post-doctoral fellow at Southeast University. From 1999 to 2000 , he was a research fellow in IRCCyN, Nantes, Frances. From 2000 to 2003, he was a research fellow at Glasgow University, Loughborough University and UMIST, UK. In 2004, he joined the Institute of Automation in Southeast University as a professor. In 2006 he became a professor at the School of Instrumentation and Opto-Electronics Engineering, and now at the School of Automation and Electronic Engineering, Beihang University, Beijing, China. His research interests include robust control, stochastic systems, fault detection, filter design and nonlinear control with their applications to aerospace systems.

Dr. Guo is an Awarder of the National Science Fund for Distinguished Young Scholars of China, and a Changjiang Distinguished Professor of the Ministry of Education of China. He has published more than 120 papers and one monograph and served as an Editor for 5 journals.

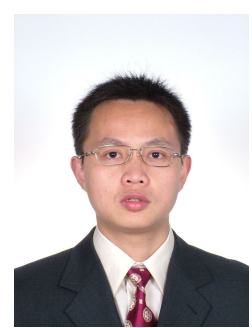

Shihua Li (SM'10) was born in Pingxiang, Jiangxi Province, China in 1975. He received his bachelor, master, Ph.D. degrees all in Automatic Control from Southeast university, Nanjing, China in 1995, 1998 and 2001, respectively. Since 2001, he has been with School of Automation, Southeast University, where he is currently a professor and the director of Mechatronic Systems Control Laboratory. His main research interests lie in modeling, analysis and nonlinear control theory (nonsmooth control, disturbance rejection control, adaptive control, etc.) with applications to mechatronic systems, including manipulator, robot, AC motor, power electronic systems and others. He has authored or coauthored over 200 technical papers and two books in these areas. He is a member of Technical Committee on System Identification and Adaptive Control of the IEEE CSS, a member of Electrical Machines Technical Committee and Motion Control Technical Committee of the IEEE IES. He serves as associate editors or editors of IET Power Electronics, International Journal of Electronics, Journal of Power Electronic, Mathematical Problems in Engineering and guest editors of IEEE Transactions on Industrial Electronics, International Journal of Robust and Nonlinear Control and IET Control Theory and Applications. $\mathrm{He}$ is a senior member of IEEE and the Vice chairman of IEEE CSS Nanjing Chapter.

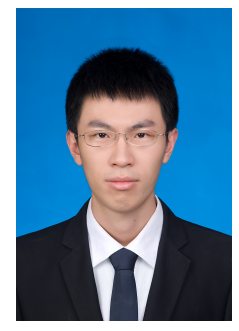

Yunda Yan (S'15) was born in Yixing, Jiangsu Province, China in 1990. He received the B.Sc degree from School of Automation in Southeast University, Nanjing, China in 2013. He is currently working toward the Ph.D. degree in control theory and control engineering from School of Automation in Southeast University.

His research interests include the development of advanced control strategies (Nonlinear Model Predictive Control, Disturbance Observer Based Control, etc.) and their applications in AC servo systems. $\mathrm{He}$ is a student member of IEEE. 